\title{
State of the art on methodologies for the development of a metadata application profile
}

\author{
Mariana Curado Malta ${ }^{1}$ and Ana Alice Baptista ${ }^{1}$ \\ Algoritmi Center, University of Minho \\ mariana.malta@algoritmi.uminho.pt and analice@dsi.uminho.pt
}

\begin{abstract}
This article presents the state of the art on methodologies for the development of a metadata application profile. For this purpose we have performed searches in scientific on-line databases and made other efforts such as global searches on the Web and calls on the mailing lists of the metadata communities to find articles and Web pages about metadata application profiles development and metadata best practices or methodologies. These searches produced 21 items of which 9 have information on how the metadata application profiles were developed. As a result of this analysis we have found small formulas or private recipes for very particular phases of the process, but none is described in detail. We have also found guidelines that were too global and not sufficiently detailed for the metadata application profile development. As far as we could determine, there is no comprehensive methodological support for the metadata application profile development.
\end{abstract}

\section{Introduction}

This article reports part of a Semantic Web related research project that deals with a framework of semantic interoperability among the world community of social and solidarity economy web based information systems. In this project it has been identified the need to develop a metadata application profile (AP) in order to achieve such interoperability [Malta and Baptista, 2012]. An application profile is a technique used to adapt to the specific needs of a certain community [Lynch, 1997]. It uses data elements from different metadata schemes and puts them together with local developments in order to adjust to a particular community [Heery and Patel, 2000]. According to the Semantic Web Activity Webpage (2012) "The Semantic Web provides a common framework that allows data to be shared and reused across application, enterprise, and community boundaries" [W3C, 2012]. In this cross-boundaries context, the development of AP is expected to be a complex task that needs an adequate methodological support. By methodology we mean a body of operations to reach a goal. A methodology shows how to operationalize defined steps. To find the adequate methodological support to develop an AP, we have performed a literature review. We carried out searches in on-line scientific databases. Then, to complement the literature review, we have performed wider searches on Google search engine ${ }^{1}$ and sent calls

\footnotetext{
${ }^{1}$ http://www.google.com - accessed in 19 July 2012
} 
to some mailing lists of the metadata cummunity. We have found small formulas or private recipes for very particular phases of the process of development of an $\mathrm{AP}$, but none is described in detail. We have also found guidelines that were too global and not sufficiently detailed for the AP development.

This article is organized in 5 sections. In Section 2 we explore the concept of an application profile in order to define the limits of our work. Section 3 presents the work methodology. Section 4 reports the findings and analyses these findings. Finally, closing conclusions and future work are drawn in section 5 .

\section{Application Profile}

Any standard was always a basis for the implementation of profiles (even before the existence of the Internet). A good example was the community Z39.50² which created profiles to refine the standard options [Baker et al., 2001]. An application profile was based on a standard, and it was a technique that helped a certain community to refine the standard to their needs [Lynch, 1997]. Later, with the Semantic Web, and with the advent of the $\mathrm{RDF}^{3}$ syntax, programmers had the technology for the combination of individual elements of a variety of different metadata schemes. It was an open gate to the possibility of choosing the most appropriate elements to describe resources [Heery and Patel, 2000]. Heery and Patel (2000) define an application profile as consisting of: "Data elements drawn from one or more namespaces schemas combined together by implementors and optimised for a particular local application" [Heery and Patel, 2000]. In 2008 Baker, Nilsson and Johnston define an application profile (DCAP - Dublin Core Application Profile) as: "A document (or set of documents) that specifies and describes the metadata used in a particular application " [Baker et al., 2008].

Dublin Core Metadata Initiative ${ }^{4}$ (DCMI) specifies the rules to implement a DCAP in its recomendation "Singapore Framework for Dublin Core Application Profiles" (see [Baker et al., 2008]). This document is a synopsis of all the research done among the metadata community until that date. It is a very important document since it defines a framework to implement semantic interoperability ${ }^{5}$ among different communities of practice.

For the sake of our work, when we refer to a metadata application profile (AP), we refer to metadata profile implementations that meet either the definitions of Lynh (1997), Heery and Patel (2000) or Baker et al. (2008).

\footnotetext{
$\overline{2}$ http://www.loc.gov/z3950/agency/ - accessed in 1.12.2011

3 A standard model for Web data interchange [W3C, 2010] - see http://www.w3.org/TR/rdf-concepts - accessed in 10 July 2012

${ }^{4}$ See http://www.dublincore.org - accessed in 19 July 2012

${ }^{5}$ Semantic interoperability focuses on meaningful exchanges of information, i.e. the information has the same interpretation (or very closely) by both the sender and the receiving systems
} 


\section{Methodology}

In order to develop our work we have devided the searches in two parts: Part I - Identification and analysis of the existing development of AP; Part II - Identification and analysis of the existing methodologies used for the development of AP.

We carried out general searches and then more refined searches in on-line databases. The databases used were: Google Scholar ${ }^{6}$, ISI Web of Knowledge ${ }^{7}$, Networked Digital Library of Thesis and Dissertations ${ }^{8}$, $^{\text {Scopus }}{ }^{9}$ and Oaister ${ }^{10}$. The searches were made in English, French, Spanish and Portuguese for Part I and in English for Part II; and in the fields 'title of the article' and 'body of the article'.

In the first phase of the searches we chose a set of articles. In the second phase, we analyzed the references of the articles chosen in the first phase, new articles where chosen due to the relevance of their title and later by the relevance of their summary. This process was iterative in what new articles were concerned, ending when articles referenced to each other. In the third phase of the searches we looked for articles citing the articles of the first phase. New articles were selected according to the same rules of the second phase.

Concerning Part I the keywords used for the searches were: Metadata Application Profile, Dublin Core Application Profile, Metadata Element Set, Metadata Scheme, and Metadata vocabulary.

Concerning Part II the keywords used for the searches were: Application Profile Methodologies, Application Profile and Methodologies, Dublin Core Application Profile Methodologies, Dublin Core Application Profile and Methodologies, Metadata and Methologies.

After the literature review, we have made efforts to find more metadata application profiles through: (i) Google ${ }^{11}$ searches with the same terms defined in the literature review; (ii) Information received by email after sending an email to the "General" DCMI mailing list ${ }^{12}$ with an information request on AP development; (iii) Information received on the "Architecture" DCMI mailing-list ${ }^{13}$.

Finally we analysed every item (text document or webpage) that came out of the searches. The methodology was as follows:

1. Every item to be analised was printed out and numbered;

2. A word processing document was created: the matrix document;

3. A new line was introduced in the matrix document with a reference (number defined in phase 1) to the new item being analysed;

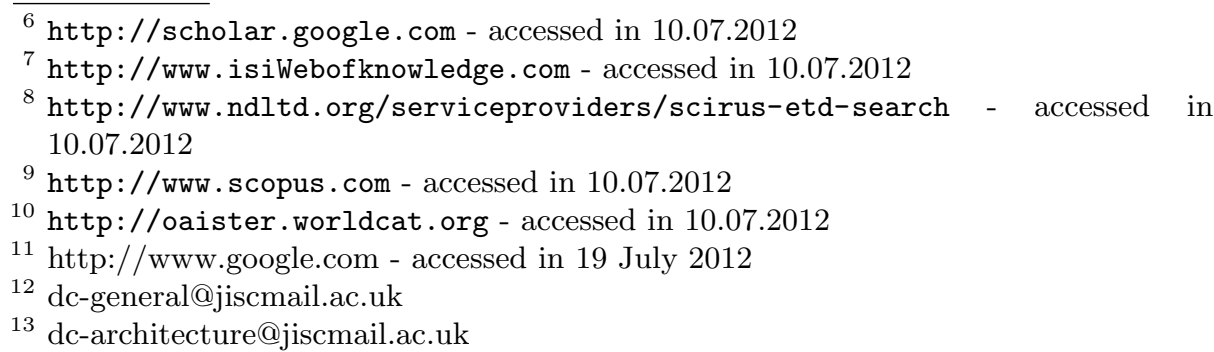


4. Every time there was important information to keep in the item analysed, it was copied to the matrix document, with a reference to the source page number (if it was an article; no number was kept if it was a web page). This phase finished every time there was no more important information to keep in the analysed item;

5. The process went back to step 3 until there was no more items to be analysed.

We have organised the items in 3 different categories:

- scientific articles, technical documents, manuals which refer explicitly to methodologies for the development of AP or methodologies concerning metadata applications or best practices. We will call them Manuals.

- a set of scientific articles that systematise information related to specific areas or even more horizontal areas. We mean articles that report the state of the art of AP of a specific domain, or analyse a certain characteristic on the AP development in a general domain basis. We will call them Methodological articles.

- finally, a set of scientific articles that report the development of AP. These articles include sections that refer to "ways of doing " or "recipes" for specific moments of the AP development. We will call them Profile articles.

\section{Results}

We analysed each of the items in the light of: (i) the steps: we call it steps; (ii) how these steps are executed: we call it how. We have set a scale of coverage range for the AP in what the "how" is concerned - we call it coverage. Basically, when the item defines the "how", we want to measure what part of the whole AP development this "how" covers: 1 - Partially covered; 2 - Moderately covered; 3 - Totally covered. When there is no "how", the coverage is defined as "n/d".

Bellow you can read the results found on each category.

\subsection{Manuals}

- Chen and Chen (2005): The Metadata Lifecycle Model is a model to systematize the metadata working procedure in digital libraries [Chen and Chen, 2005]. It has 4 stages:

1. Requirement Assessment and Content Analysis:

- Acquisition of Metadata Base Needs;

- Review of Relevant Metadata Standards and Projects ;

- Investigation of Deep Metadata Needs;

- Identification of Strategies for the Metadata Schemes and Achieving Interoperability with Well-known Metadata Standards.

2. System Requirement Specification;

- Preparation of the Metadata Requirement Specification;

- Evaluation of Metadata Systems.

3. Metadata System; 
- Preparation of Best Practice Guidance;

- Development of the Metadata System .

4. Service and Evaluation

- Maintenance of Metadata Service ;

- Evaluation of Metadata Performance.

Steps: Yes; How: No; Coverage: n/d

- BSI (2005): Makes recommendations about data models for any organisation creating application profiles of international metadata standards, for use in the domain of teaching and learning [BSI, 2005]. Focuses on the two standards: Dublin Core Metadata Element Set and IEEE LOM.

Steps: Yes; How: No; Coverage: n/d

- IMS Global Learning Consortium (2005a) (2005b) : Developed by IMS Global Learning Consortium, specify the steps for developing an AP. Part 1 focuses on issues that are related to the management process and methodology. Second part is purely technical. Part 1 has an "Outline of a Process for Creating an Application Profile" section which presents, in a very global way, the steps for the development of an AP in the domain of learning objects. Bellow we summarize the most important steps:

1. Feasibility and Risk Analysis: to identify the stakeholders; to determine the size of the community market;

2. Capturing the Requirements: to identify the specific requirements of the community that is going to use the AP;

3. Project Group Guidelines: generic guidelines on how to develop the AP, using tools like scenarios and case studies, and also some group techniques.

Also has a defined set of rules for the AP development to be found in the next group of documents. These rules have to do with compliance issues with the base schemas used on AP.

Steps: Yes; How: Yes; Coverage: 1

- CWA (2006): Created in 2006 by the European Committee for standardisation. It is a guide for the development of AP in the area of e-learning. Shows the major guidelines, giving examples on how to define the metadata elements of the AP: advises on the creation of a matrix having the data elements as lines and the properties of the data elements as columns. The major guidelines are:

1. Definition of the own requirements;

2. Selection of the data elements;

3. Definition of the obligation of data elements;

4. Definition of the value space;

5. Definition of the relationship and dependency;

6. Definition of the data type profiling;

7. Definition of the technical binding.

Steps: Yes; How: Yes; Coverage: 1

- Baker et al. (2008): The Singapore framework defines what a DCAP is and presents the rules for its development:

1. Definition of the functional requirements (mandatory); 
2. Definition of the domain model (mandatory);

3. Description Set Profile (mandatory);

4. Usage guidelines (optional);

5. Encoding syntax guidelines (optional).

Steps: Yes; How: No; Coverage: n/d

\subsection{Methodological articles}

- Duval et al. (2002): presents practices of metadata, one of them being the use of AP. It shows rules and key issues. Summary of the manual CWA (2006).

Steps: No; How: No; Coverage: n/d

- Friesen et al. (2002) : presents a set of topics that are important for the implementation of AP in the domain of learning objects. Uses as examples two AP (TLF and CanCore). Advise on some techniques: the use of a good data model, the use of good practice examples, the use of standard base schemes, the use of incremental actions in order to achieve the final goal of interoperability.

Steps: Yes; How: No;Coverage: 1

- Currie et al. (2002): Provides a method for making "interoperability visible". The approach is to aggregate all elements of the different metadata resources colections, "consider the processes thatcould be used to rationalise the aggregated set of elements and then show how the agencies might work together to harmonise the resulting application profile. This process is referred to as ARH - HA!: visualise the processes of aggregate, rationalise, and harmonise in order to be motivated to harmonise commonly-owned, distributed, heterogenous metadata collections" [Currie et al., 2002, p. 179].

Steps: No; How: Yes;Coverage: 1

- EESV (2012) : The European project ISA, which has recently developed the AP "ADMS", makes available in its documentation a document dedicated to the methodology of the management of a cross-cultural and geographically distributed group that builds the AP. But it does not show any information concerning the methodology for the AP development.

Steps: No; How: Yes; Coverage: 1

\subsection{Profile articles}

- DCMI (nd): Proposes the use of scenarios for their AP development.// Steps: No; How: Yes; Coverage: 1

- Onyancha et al. (2001): Reports the development of the AP "AGRIS", in the agriculture domain. It has a reference to the methodology used [Onyancha et al., 2001, pag. 7]:

1. Development of a conceptual map of the different types of information resources used in the AGRIS project portal;

2. Remodelling of the project data model to meet current information needs (such as description of Web pages and databases); 
3. Evaluation of standards and common resource description practices;

4. Mapping of currently used elements to the available element pool from the standards ;

5. Proposing the unavailable elements and schemes to be included in the AP;

6. Binding.

Steps: No; How: No; Coverage: n/d

- Agostinho et al. (2004): Shows the first steps on the development of the AP "LOMAP" in the learning objects domain. Some methodological steps, they are:

1. To perform an AP literature review on AP of the same application domain;

2. To choose a base metadata schema as the starting point;

3. To apply the elements of the base schema to a set of resources in order to understand the strengths and weaknesses of these elements, and to remove the issues that can arise from this application.

4. To analyse the results of the previous step;

5. To apply an existing application profile to a sample of learning objects;

6. To analyze the results of the previous step;

7. To develop the AP based on the previous steps.

Steps: Yes; How: Yes; Coverage: 1

- de La Passadiere and Jarraud (2004): Reports the development of the French AP "ManUel", in the learning objects domain. The guidelines are based on the study of user needs and community of practice of the AP. The guidelines are [de La Passadière and Jarraud, 2004, pag. 10]:

1. To study the needs: consulting the different user communities; studying the standards;

2. To develop a solution: define the adopted principles; justify the choices made;

3. To develop the AP.

Steps: Yes; How: No; Coverage: $n / d$

- Marzal Garcı-Quismondo et al. (2006): Reports the development of the Spanish AP "MIMETA", in the learning objects domain. The reported methodology is based on both documents Agostinho et al. (2004) and Chen and Chen (2005) [Marzal García-Quismondo et al., 2006, pag. 553]:

1. A literature review on educational metadata and analysis of the major standards and specifications developed in the field of educational technologies;

2. An analysis of the main educational digital library projects;

3. Development of an AP with the main identified standards: to choose initially the more generic elements, then to choose the more detailed elements.

Steps: Yes; How: No; Coverage: n/d

- Wilson et al. (2007): Reports the development of the AP "MAP", in the libraries domain. It refers that the approach to the AP was influenced by BSI (2005) [Wilson et al., 2007, pag. 7]: 
1. Gather requirements;

2. Identify appropriate schemes;

3. Select data elements;

4. Specify rules for data elements;

5. Review against other requirements;

6. Finalise draft;

7. Create crosswalks;

8. Scope requirements for XML Binding;

9. Develop a maintenance plan.

Steps: Yes; How: No; Coverage: n/d

- Buonazia and Masci (2007): Reports the development of the AP "PICO" under the scope of the "Cultura Italia" project , in the cultural heritage domain. Has a whole section about the methodology used in PICO development. We summarise [Buonazia and Masci, 2007, pag. 394]:

1. users and domain analysis;

2. definition of user scenarios and user cases;

3. overall architecture design;

4. content analysis;

5. analysis of the state of the art on descriptive metadata standards;

6. design of the metadata scheme;

The methodology has more steps but they are not related to the AP development.

\section{Steps: Yes; How: Yes; Coverage: 1}

- Eadie (2008): Reports that a working group has been launched composed by people from different backgrounds related to the AP application domain. It also refers that when the project is completed there is the intention to broaden the discussion to a wider consultant group. The workplan is presented:

1. Draft development of the functional requirements;

2. Draft development of the Entity-Relationship diagram and the set of attributes;

3. Draft development of the AP;

4. Group discussion;

5. AP refinement with the information coming from group discussions;

6. Development of simple catalogue guides for AP use;

7. Work presentation to the community;

8. Development of acceptance plans for the community.

Steps: Yes; How: Yes; Coverage: 1

- Salokhe et al. (2008): Reports the development of the AP Organization, in the domain of Agriculture. The methodology used for its development was [Salokhe et al., 2008, pag. 3]:

1. Project definition, its goal and context;

2. Existing metadata standards assessment and creation of metadata scheme;

3. Comparison of each defined element with the ISO11179 standard elements;

4. XML binding development; 
5. Real data testing with the binding defined in the previous item;

6. Guidelines development;

Steps: Yes; How: No; Coverage: $\mathrm{n} / \mathrm{d}$

- Bountouri et al. (2009): Reports the development of the "PSI" AP, in the domain of Public Service Information. It has one section for presentation of the implementation methodology of the AP. It broadly presents [Bountouri et al., 2009, pag.4]:

1. Comparison of every metadata standard with "DC" and Addition of extra properties and sub-properties;

2. Semantic resolution and harmonisation of properties and sub-properties;

3. Specification of the "PSI" AP.

Steps: Yes;How: No; Coverage: n/d

- Palavitsinis et al. (2009): Reports the development of the "Organic.Edunet" $\mathrm{AP}$, in the domain of agriculture learning resources. In the section "generic process for an AP development", refers the generic steps used for its development, as follows:

1. Definition of the "Organic.Edunet " requirements;

2. Selection of IEEE LOM ;

3. Semantic refinement (so as to serve better the needs of the Organic.Edunet);

4. Specification of the constraints and the domains of the elements;

5. Specification of the element relationships and dependencies;

6. Introdution of new elements to respond to specific needs;

7. AP completion (which includes binding and technological issues of how metadata is obtained, created and stored).

Steps: Yes; How: No;Coverage: n/d

- Zschocke et al. (2009): Reports the development of the "CIGAR" AP, in the domain of learning objects. It is targeted at distributed and multilanguage community. Reports a revision of different AP IEEE LOM based to identify the mandatory IEEE LOM elements used in the AP implementation of other organisations. This helped to understand better the elements sub-set which are normally used to describe the basic learning objects caracteristics and their influence in the development of the "CIGAR" AP. Due to the international destributed nature of the community, the multi-language support was considered essential [Zschocke et al., 2009, pag. 16]. Steps: Yes; How:

Yes; Coverage: 1

\subsection{Analysis}

From the 21 analised items only 9 have information on how to develop an AP, but they were all scaled as "partially covered" in what the AP development coverage is concerned. Baker et al. (2008) is the most comprehensive document concerning the development of an AP, but it doesn't actually explain in detail how to develop it. This document is the climax of a process of development of stored knowledge, coming from Heery and Patel (2000) and Duval et al. (2002), through IMS Global Learning Consortium (2005a) and IMS Global Learning Consortium (2005b), ending in CWA (2006). We came across a few guidelines 
or "hows" in specific parts of the development process which are interesting and should be kept for future work. But these guidelines, specially in the documents catalogued as "Profile articles", are too centered in a particular domain. These guidelines are presented in table 1.

\section{Conclusions and future work}

We have made the state of the art on the methodologies used for a metadata application profile (AP) development. The study consisted of a literature review and other efforts to find scientific articles, manuals, reports, documents or webpages about AP development methodologies, metadata best practices methodologies, AP or AP development. We have found small formulas or private recipes for very particular phases of the process, but none is described in detail. We have also found global guidelines that were not sufficiently detailed for the AP development. As far as we could determine, there is no comprehensive methodological support for the metadata AP development. In a cross-boundaries context, as it is the context of the Semantic Web, the development of AP is expected to be a complex task that needs an adequate methodological support. The metadata community would benefit from a detailed cross-domain methodology. It is our aim to contribute to the definition of a comprehensive methodological support for the development of an AP. For the short-term future work, we plan to finalize the study on AP and report to the metadata community our findings under two axis: (i) Identification and analysis of the existing metadata application profiles; (ii) Temporal evolution of the AP. AP are specific kinds of data models; it is reasonable to think that the already well established methodologies for the development of data models in the scope of software engineering can be useful, as a basis, to the AP development. Therefore, our next goal will be to study in detail the more representative methodologies for the development of data models in the context of the software engineering and, then, analyse and combine them with the specific needs of AP, especially in what regards global interoperability concerns.

\section{Acknowledgement}

This article was presented at the MTSR2012 conference, in Cádiz November 2012, with the support of Fundação para a Ciência e Tecnologia - Projecto Estratégico do Centro Algoritmi - Ref.: FCOMP-01-0124-FEDER-022674.

J.M. Dodero, M. Palomo-Duarte, P. Karampiperis (Eds.): MTSR 2012, CCIS 343, pp. 61-73, 2012.

(c)Springer-Verlag Berlin Heidelberg 2012.

\section{References}

[Agostinho et al., 2004] Agostinho, S., Bennett, S., Lockyer, L., and Harper, B. (2004). Developing a learning object metadata application profile based on lom suitable for 


\begin{tabular}{|c|c|}
\hline [Allinson and Powell, 2006] [Eadie, 2008] & Workgroups composed by people of different profiles \\
\hline [de La Passadière and Jarraud, 2004] & $\begin{array}{l}\text { The support in the AP development of workgroups within } \\
\text { the target community }\end{array}$ \\
\hline $\begin{array}{l}\text { [Chen and Chen, 2005], [BSI, 2005], } \\
\text { [IMS Global Learning Consortium, 2005a], } \\
{[\text { CWA, 2006], }} \\
\text { [de La Passadière and Jarraud, 2004] } \\
\text { and [Eadie, 2008] }\end{array}$ & $\begin{array}{l}\text { The need for a requirement analysis, however in none of } \\
\text { these documents can we find any form of development } \\
\text { procedure }\end{array}$ \\
\hline $\begin{array}{l}\text { [Chen and Chen, 2005], [BSI, 2005], } \\
\text { [Onyancha et al., 2001], } \\
\text { [Agostinho et al., 2004], } \\
\text { [Marzal García-Quismondo et al., 2006], } \\
\text { [Buonazia and Masci, 2007] } \\
\text { [Salokhe et al., 2008] }\end{array}$ & $\begin{array}{l}\text { The need for a state of the art development of the } \\
\text { AP and metadata standard schemes. The documents } \\
\text { further refer that a state of the art can be accomplished } \\
\text { through: (i) a literature review ([Agostinho et al., 2004], } \\
\text { [Marzal García-Quismondo et al., 2006]);(ii) project } \\
\text { study ([Marzal García-Quismondo et al., 2006] and } \\
\text { [Buonazia and Masci, 2007]); (iii) standards evaluation } \\
\text { and study of common practices ([Onyancha et al., 2001]) }\end{array}$ \\
\hline $\begin{array}{l}{[\text { Agostinho et al., 2004] and }} \\
{[\text { Marzal García-Quismondo et al., 2006] }}\end{array}$ & $\begin{array}{l}\text { The need for choice of one or more base metadata } \\
\text { schemes as a starting point. }\end{array}$ \\
\hline & $\begin{array}{l}\text { The need for metadata elements specification is defined } \\
\text { in all documents, in fact the core of the AP development. } \\
\text { There is no reference to how this should be undertaken. } \\
\text { However there are a few guidelines: }\end{array}$ \\
\hline $\begin{array}{l}\text { [IMS Global Learning Consortium, 2005a], } \\
\text { [Friesen et al., 2002], [DCMI, nd] and } \\
\text { [Buonazia and Masci, 2007] }\end{array}$ & Through scenario building and case construction. \\
\hline [Agostinho et al., 2004] & $\begin{array}{l}\text { Through the application of the chosen base metadata } \\
\text { scheme elements to a set of resources. This work is done } \\
\text { in two steps: (i) element application to a resource sample } \\
\text { and respective subsequent analysis; (ii) answer to a set } \\
\text { of questions and respective subsequent analysis. }\end{array}$ \\
\hline [Marzal García-Quismondo et al., 2006] & $\begin{array}{l}\text { Through the choice of element of: (i) generic caracteris- } \\
\text { tics of the base schemes; (ii) specific caracteristics of the } \\
\text { base schemes. }\end{array}$ \\
\hline $\begin{array}{l}\text { [Baker et al., 2008], } \\
\text { [Onyancha et al., 2001], [Eadie, 2008] }\end{array}$ & $\begin{array}{l}\text { The need to prepare a data model is refered in many doc- } \\
\text { uments. This model, in the case of Baker et al. (2008), } \\
\text { can be expressed only through text or using a more for- } \\
\text { mal approach, as UML; in the case of Eadie (2008) the } \\
\text { diagram entity-relationship is used. }\end{array}$ \\
\hline$[\mathrm{CWA}, 2006]$ & $\begin{array}{l}\text { For the definition of the metadata elements, they sugest } \\
\text { the creation of a matrix having the data elements as lines } \\
\text { and the properties of the data elements as columns. }\end{array}$ \\
\hline
\end{tabular}

Table 1. Important guidelines found on the analysis to be kept for future work 
the australian higher education context. Australasian Journal of Educational Technology, 20(2):191-208.

[Allinson and Powell, 2006] Allinson, J. and Powell, A. (2006). Swap application profile. http://www.ukoln.ac.uk/repositories/digirep/index/SWAP. Acedido em 1 de Junho 2012.

[Baker et al., 2001] Baker, T., Dekkers, M., Heery, R., Patel, M., and Salokhe, G. (2001). What terms does your metadata use? application profiles as machineunderstandable narratives. Journal of Digital Information, 2(2):10.

[Baker et al., 2008] Baker, T., Nilsson, M., and Johnston, P. (2008). The singapore framework for dublin core application profiles. http://dublincore.org/documents/ singapore-framework/. Accessed in 26.06.2011.

[Bountouri et al., 2009] Bountouri, L., Papatheodorou, C., Soulikias, V., and Stratis, M. (2009). Metadata interoperability in public sector information. Journal of Information Science, 35(2):204-231.

[BSI, 2005] BSI (2005). BS 8419-1:2005 Interoperability between metadata systems used for learning, education and training. Code of practice for the development of application profiles. BSI.

[Buonazia and Masci, 2007] Buonazia, I. and Masci, M. (2007). Il pico application profile. un dublin core application profile per il portale della cultura italiana.

[Chen and Chen, 2005] Chen, Y. and Chen, S. (2005). Metadata lifecycle model and metadata interoperability. In 5th International Conference on Conception of Library and Information Science.

[Currie et al., 2002] Currie, M., Geileskey, M., Nevile, L., and Woodman, R. (2002). Visualising interoperability: Arh, aggregation, rationalisation and harmonisation. In Proceedings of the 2002 international conference on Dublin core and metadata applications: Metadata for e-communities: supporting diversity and convergence, pages 177-183. Dublin Core Metadata Initiative.

[CWA, 2006] CWA (2006). Guidelines and support for building application profiles in e-learning (CEN Workshop Agreement, CWA 15555:2006 E). CEN, European Committee for Standardization, ftp://ftp.cenorm.be/PUBLIC/CWAs/e-Europe/WS-LT/ cwa15555-00-2006-Jun.pdf. Acedido em 2 de Julho de 2012.

[DCMI, nd] DCMI (n/d). Dublin core education application profile (working draft of v0.4). https://docs.google.com/Doc?id=dn8z3gs_38cgwkvv. Acedido em 2 de Junho de 2012.

[de La Passadière and Jarraud, 2004] de La Passadière, B. and Jarraud, P. (2004). Manuel, a lom application profile for c@mpusciences®. Sciences et Technologies de l Information et de la Communication pour l Éducation et la Formation, 11.

[Duval et al., 2002] Duval, E., Hodgins, W., Sutton, S., and Weibel, S. (2002). Metadata principles and practicalities. D-lib Magazine, 8(4):16.

[Eadie, 2008] Eadie, M. (2008). Towards an application profile for images. Ariadne, 55.

[EESV, 2012] EESV, P. E. S. (2012). Process and methodology for core vocabularies. Technical report, Interoperability solutions for European Public Administrators.

[Friesen et al., 2002] Friesen, N., Mason, J., and Ward, N. (2002). Building educational metadata application profiles. In Proceedings of the International Conference on Dublin Core and Metadata for e-Communities, volume 2002, pages 63-69.

[Heery and Patel, 2000] Heery, R. and Patel, M. (2000). Application profiles: mixing and matching metadata schemas. Ariadne, 25:27-31.

[IMS Global Learning Consortium, 2005a] IMS Global Learning Consortium, I. (2005a). IMS Application Profile Guidelines: Part 1 - Management Overview. IMS Global Learning Consortium, Inc., version 1 edition. 
[IMS Global Learning Consortium, 2005b] IMS Global Learning Consortium, I. (2005b). IMS Application Profile Guidelines: Part 2 - Technical Manual. IMS Global Learning Consortium, Inc., version 1.0 edition.

[Lynch, 1997] Lynch, C. A. (1997). The z39.50 information retrieval standard - part i: A strategic view of its past, present and future. D-Lib Magazine.

[Malta and Baptista, 2012] Malta, M. and Baptista, A. (2012). Social and solidarity economy web information systems: State of the art. In Vidal, A. and Torres, T., editors, Social e-Entreprise: Value Creation through ICT, chapter 1. IGI Global. in press.

[Marzal García-Quismondo et al., 2006] Marzal García-Quismondo, M., Calzada Prado, J., and Cuevas Cerveró, A. (2006). Desarrollo de un esquema de metadatos para la descripción de recursos educativos: el perfil de aplicación mimeta. Revista española de documentación científica, 29(4):551-571.

[Onyancha et al., 2001] Onyancha, I., Keizer, J., and Katz, S. (2001). A dublin core application profile in the agricultural domain. In International Conference on Dublin Core and Metadata Applications, number 0, pages pp-185.

[Palavitsinis et al., 2009] Palavitsinis, N., Manouselis, N., and Sanchez Alonso, S. (2009). Evaluation of a metadata application profile for learning resources on organic agriculture. Metadata and Semantic Research, pages 270-281.

[Salokhe et al., 2008] Salokhe, G., Pesce, V., and Liesthout, J. (2008). Organization metadata application profile. Technical report, FAO.

[W3C, 2010] W3C (2010). Rdf - w3c standards. http://www.w3.org/RDF/. Acessed in 14.01.2012.

[W3C, 2012] W3C (2012). W3c semantic web activity. http://www.w3.org/2001/sw/. Accessed 30 Jul 2012.

[Wilson et al., 2007] Wilson, K., Billington, L., Moir, S., and Carpenter, S. (2007). Development of a metadata application profile at the state library of new south wales. Library Papers, page 4.

[Zschocke et al., 2009] Zschocke, T., Beniest, J., Paisley, C., and Najjar, J. (2009). The lom application profile for agricultural learning resources of the cgiar. International Journal of Metadata, Semantics and Ontologies, 4(1):13-23. 